\title{
Ideologia em abundância nas Revistas Época e Veja: a revanche marxista
}

Alexandre Maia do Bomfim

Professor do Instituto Federal de Educação, Ciência e Tecnologia do

Rio de Janeiro

\section{Resumo}

Estudo sobre como as revistas "Veja" e "Época" tratam do tema Educação. O corpus da pesquisa foi a leitura de 81 matérias. A pesquisa começa mapeando as condições de produção das revistas, identificando alguns intelectuais orgânicos. Alcançou que as revistas defendem a meritocracia, a participação empresarial na educação, dissociam a valorização do docente da melhoria da educação formal, etc. E o mais importante, fazem tudo isso sob um véu de neutralidade e imparcialidade.

Palavras-chaves: Educação e Mídia; Educação e Ideologia; Intelectuais e Educação.

\section{Abstract}

Study on the magazines as "Veja" and "Época" deal with the theme Education. The research was the reading of 81 texts. The research begins by mapping the conditions of production of magazines, identifying some intellectuals. Reached the magazines advocate meritocracy, participation in business education, dissociate the enhancement of teaching improvement of formal education. And most importantly, are all under a veil of neutrality and impartiality.

Keywords: Education and Media, Education and Ideology, Intellectuals and Education. 


\section{Introdução}

Os detentores do poder são levados a crer que o ponto de vista deles é, por si mesmo, universal. Essa convicção é transmitida a toda a sociedade (Konder-2006, p. 86).

proposta deste texto é desafiadora por seu teor evidentemente
político, a de tecer uma crítica aos intelectuais orgânicos que
estão por trás das mais lidas revistas semanais do país, Época e Veja. Parte da hipótese inicial, de que tais revistas: (1) tratam os profissionais de educação como os principais responsáveis pelo baixo rendimento de nossa educação, porque seriam desqualificados e filiados a uma perspectiva não-científica; (2) não enxergam nenhuma outra possibilidade que não passe pela meritocracia (por princípio, excludente); (3) desassociam investimento em salários da melhoria no ensino, ao mesmo tempo, que contraditoriamente defendem a relação direta entre investimento educacional e desenvolvimento econômico (a conhecida Teoria do Capital Humano); (4) responsabilizam parcialmente os governantes (no quesito burocratização), enquanto isentam totalmente outros segmentos da sociedade, desde a família, à mídia até os organismos e instituições sociais.

Tal hipótese inicial, que para alguns cientistas sociais ${ }^{1}$ tratar-se-ia de uma obviedade ululante, poderia, num certo sentido, ser questionada quanto à relevância. Não obstante, em Ciência não há obviedade. Destarte, dizer que as revistas semanais possuem um conteúdo ideológico em suas reportagens é um pressuposto, porém vale saber o quanto e como se estrutura num discurso articulado? Primeiro ponto a justificar este artigo é a necessidade de evidenciar que há um debate. A mídia, de uma maneira geral, se posiciona imparcial e sugere que seus conteúdos sejam factuais, desse modo martelam com muita regularidade e massivamente seu ponto de

${ }^{1}$ Emir Sader chega a dizer sobre a Veja: Seus colunistas são o melhor exemplo da vulgaridade e da falsa cultura na imprensa brasileira. Uma lista de propagandistas do bushismo, escolhidos seletivamente, reunindo a escritores fracassados, a ex-jornalistas aposentados, a autores de auto-ajuda, a profissionais mercantis da educação, misturandose e mesclando esses temas em cada uma das colunas e nos editoriais do dono da revista. Uma equipe editorial de nomes desconhecidos cumpre a função de "cães de guarda" dos interesses dos ricos e poderosos - que, em troca, anunciam amplamente na revista - de plantão. [Carta Maior, 30/10/2005] (SADER, 2005). 
vista e, o pior, trazem de forma insuficiente as posições dos intelectuais contrários. Dominique Maingueneau aponta que essa é uma característica muito peculiar aos "mediadores", que se põem como "transparentes":

[...] É preciso, de uma maneira ou outra, considerar o modo de existência destes grupos que negam constantemente sua importância, ao se considerarem transparentes: fiéis zelosos, simples técnicos, representantes dos trabalhadores, consumidores, etc., sempre se apresentam como portadores de mensagens (MAINGUENEAU, 1997, p.55).

Todas as possibilidades de reagir à suposta transparência dos meios de comunicação já seria uma boa justificativa. Cada oportunidade de reagir ao discurso de neutralidade e transparência produzido, no caso, pelas Revistas Semanais se torna importante (quase quixotesca) por ser muito menor em relação à proporção de pessoas que elas alcançam. A proposta aqui é a de um texto objetivo, logo, a seguir apresentaremos nossas referências e passos metodológicos. Vale dizer agora que, indo além da hipótese inicial, nosso eixo de trabalho (e recorte) é apreender a proposta educacional das Revistas Semanais, Veja e Época, procurando demonstrar que elas, não de forma homogênea, contradizem um dos pontos que lhes é mais caro e são hoje, de forma indisfarçável: extremamente ideológicas!

\section{Nossas referências}

Os filósofos se limitaram a interpretar o mundo de diferentes maneiras; mas o que importa é transformá-lo (Marx nas Teses contra Feuerbach).

Começar esta parte com a epígrafe acima de Marx talvez seja a nossa maneira de limar de vez o aspecto positivista ${ }^{2}$ do texto. Ao mesmo tempo, serve para marcar uma forma de analisar as revistas, em que se pretende o rigor científico, mas sem a presunção metafísica de se posicionar neutro e com uma objetividade estanque. É interessante que seja Marx, pois com ele

\footnotetext{
${ }^{2} \mathrm{O}$ que se espera do dispositivo do analista é que lhe permita trabalhar não numa posição neutra mas que seja relativizada em face da interpretação (ORLANDI, 2005, p. 61).
} 
vem o espectro do socialismo, algo que as revistas em questão querem garantir grande distância:

Os professores esquerdistas veneram muito aquele senhor que viveu à custa de um amigo industrial, fez um filho na empregada da casa e, atacado pela furunculose, sofreu como um mártir boa parte da existência. Gostam muito dele, fariam tudo por ele, menos, é claro, lê-lo - pois Karl Marx é um autor rigoroso, complexo, profundo que, mesmo tendo apenas uma de suas idéias ainda levada a sério hoje - a Teoria da Alienação -, exige muito esforço para ser compreendido (VEJA, 2008).

A passagem acima da Revista Veja é emblemática, tem um recurso de retórica interessante, pois primeiramente faz uma crítica contundente a Marx, mas depois procura demonstrar que o conhece mais que os seus débeis seguidores. O primeiro item de nossa metodologia não é ver a veracidade disso, mas tomar o cuidado de não fazer o mesmo que a Revista, que dissimuladamente defende um ponto de vista, mas não o assume. Desde o início nos posicionamos críticos às Revistas, assumimos um viés que permite ao leitor filtrar nossos exageros. A ortodoxia não está somente nos grupos que assim identificamos, pode estar também em nossa maneira de proceder com eles, quando os tratamos de forma monolítica, quando também não dialogamos e/ou não pontuamos nossas discordâncias. Nessa maneira de pensar vale trazer um Gramsci também muito pouco conhecido:

Na discussão científica, já que se supõe que o interesse seja a busca da verdade e o progresso da ciência, demonstra ser mais 'avançado' aquele que adota o ponto de vista segundo o qual o adversário pode expressar uma exigência que deve ser incorporada, ainda que como um momento subordinado, à sua própria construção (apud KONDER, 1992, p. 140).

Dos adversários devemos apreender o ponto mais avançado e não o mais frágil, acrescento que com o saudável risco de nos obrigar a rever nossa própria perspectiva teórica. Nossa maneira de fazer isso foi fazer uma leitura longitudinal das revistas sobre o tema "educação", numa razoável amostra de 35 reportagens da "Revista Época". Da "Revista Veja" fizemos a leitura de 46 reportagens e mais 19 artigos do articulista Cláudio de Moura Castro. O total de textos lidos é de 100 (sendo este o corpus da pesquisa). 
Duas referências nos ajudaram nessa tarefa foram Orlandi (2005) e Kosik (1976). A primeira trabalha com Análise de Discurso ${ }^{3}$ e o segundo é um filósofo marxista. Antes que isso pareça um ecletismo metodológico, vale dizer que Orlandi é imprescindível para este tipo de análise de conteúdo, assim como o Kosik que aqui trouxemos é, o menos lido, o dos capítulos finais de sua principal obra, a Dialéctica do Concreto. Esse Kosik nos permite uma forma de análise, que não estaria assentada no elemento supostamente principal de cada texto, mas nos outros elementos, que poderíamos considerar marginais ${ }^{4}$, ou melhor, ocultos.

Há três pontos, que se complementam, sugeridos por nossas referências para analisar as revistas. O primeiro aponta a pertinência de contextualizar ao máximo possível o texto, saber dos autores, das questões políticas que o precede, de onde se fala, para quem se fala, etc. É a forma de trazer o texto às suas condições de produção, estabelecer as relações que ele mantém com sua memória e também remetê-lo a uma formação discursiva - e não outra - para compreendermos o processo discursivo que indica [...] (ORLANDI, 2005, p.42). Não obstante, o segundo ponto é a compreensão de que os elementos do contexto (o universo do discurso) são infinitos. A apreensão de um discurso vai além das palavras expressas. Considerado os primeiros, vamos ao terceiro ponto:

[...] O texto, porém, pode dizer alguma coisa diferente dos testemunhos [a opinião subjetiva dos autores]: pode dizer mais, ou menos, a intenção pode não se ter realizado ou ter sido ultrapassada, e no texto (na obra) há mais do que o autor pretendia (KOSIK 1976, p.141).

\footnotetext{
${ }^{3}$ A utilização de alguns instrumentos da $\mathrm{AD}$ aqui vai ao encontro da orientação de Eni Orlandi (2005), nossa principal deferência: [...] colocar-se na posição de analista e investir nos conhecimentos que poderão expandir seu campo de compreensão. [...] terá ao menos a noção de que a relação com a linguagem não é jamais inocente, não é uma relação com as evidências e poderá se situar face à articulação do simbólico com o político (p.95).

${ }^{4}$ [...] o texto pode desenvolver e desempenhar várias funções nas quais o seu elemento específico não está presente. [...] Pode-se incluir na história das ideologias dramas, poesias, romances e novelas, abstrair-se da especificidade do seu gênero e examiná-los exclusivamente como manifestações de concepções do mundo (KOSIK, 1976, p. 144).
} 
Há sempre em qualquer texto algo que escapa à intenção do autor, outros elementos que não focam o conteúdo específico (conforme Kosik), informações paralelas que podem advir da descrição de um cenário, da época, do uso de determinadas palavras, das referências, etc. Há uma variedade de vetores, alguns inapreensíveis ao próprio autor do discurso. Os elementos destacáveis dependem da pergunta que se faz ao texto. A intenção de nossa análise não é se ater às informações paralelas e sim captar mais do que o autor pretendia (ibid.), captar o "ato falho" do autor, na verdade, aquilo que está velado. Uma prática de leitura que procura escutar o não-dito naquilo que é dito, como presença de uma ausência necessária (ORLANDI, 2005, p. 34).

Auxiliados por essa compreensão faremos análise das revistas, inicialmente às condições de produção através dos intelectuais orgânicos.

\section{As condições de produção: os intelectuais orgânicos das revistas}

[...] quais são as condições [para se ter] interesse na verdade, em vez de ter, como em outros jogos, a verdade de seus interesses? (Pierre Bourdieu no seu texto "Campo Cientifico", p. 141).

Primeiramente vamos à ficha técnica. A Veja é a maior revista semanal de informação do Brasil, em outubro de 2008 totalizou mais de 1.000.000 de exemplares em circulação, sendo que a maior parte é de assinantes (921.868), com uma projeção de 8.677.000 leitores. Somente grandes grupos empresariais conseguem publicar na Revista, cujos preços de anúncio variam entre 100.000 até 500.000 reais $^{5}$. Os preços de anúncio da Revista Época também são altos, mas menores do que os da Veja, que vão de 57.000 até 322.000 reais $^{6}$. A circulação de Época também é bem menor, geralmente menos da metade da $\mathrm{Veja}^{7}$, para o mesmo ano. De

${ }^{5} \mathrm{cf}$. http://publicidade.abril.com.br/homes.php?MARCA=47

${ }^{6} \mathrm{cf}$. http://editoraglobo.globo.com/publiedglobo_revistas_EP.htm

${ }^{7} \mathrm{cf}$.

http://www.direitoacomunicacao.org.br/novo/content.php?option=com content\&task=view $\underline{\text { id }}=2793$ 
qualquer forma, as duas revistas juntas são as que mais atingem o público das classes médias e altas (classes A e B e faixa etária entre 25 e $39 \operatorname{anos}^{8}$ ), ou seja, os formadores de opinião.

Não há condição de apreendermos integralmente a subjetividade dos autores das revistas e nem a totalidade dos intelectuais orgânicos das Revistas, há muitos que assinam as reportagens de educação ${ }^{9}$, há também os que não assinam e os camuflados nos editoriais. Não obstante, escolhemos dois intelectuais que foram e ainda são influentes nas Revistas. Um deles é o educador Cláudio de Moura Castro - CMC, principal colunista da Veja, consultor principal de quase todas as reportagens para o tema Educação. Outro teve uma influência mais à distância, porém determinante para o tema educação, na Revista Época, o diretor de jornalismo da Globo (grupo empresarial dessa Revista), Ali Kamel. Esses intelectuais orgânicos apareceram aqui mais por um motivo, lembrar que no fundo, escondido pelo texto e pela autoria há um sujeito histórico, ideológico e com determinadas intenções, como todos nós, e, principalmente, para derrubar a impressão de que aquilo que é dito só poderia ser dito daquela maneira (ORLANDI, 2005, p. 65).

CMC tem formação em economia, com uma vasta participação na vida acadêmica, foi Diretor Geral do Capes/Mec, professor de universidades como a PUC-Rio e a Fundação Getúlio Vargas, atualmente é conselheiro do Banco Interamericano de Desenvolvimento - BID e Presidente do Conselho Consultivo da Faculdade Pitágoras e como já foi dito escreve regularmente na Revista Veja ${ }^{10}$.

\footnotetext{
${ }^{8}$ cf. http://publicidade.abril.com.br/geral_perfil_leitor.php

${ }^{9}$ Alguns nomes mencionados à frente. Vale também destacar Instituições como intelectuais orgânicos. Destacamos duas instituições que são as mais recorrentes e não somente aparecem no momento de debate, mas que prestam serviço da consultoria educacional (e que infelizmente não dará para analisar): Fundação Victor Civita (do próprio Grupo Abril) e Fundação Lemann (do banco Garantia e IBMEC).

10 Todas essas informações podem ser adquiridas no site do próprio autor: http://www.claudiomouracastro.com.br/. Onde também podem ser encontrados seus artigos.
} 
De CMC analisamos 19 textos que vão de junho de 2006 até

fevereiro de 2008. Vale tabulá-los abaixo com títulos e subtítulos:

Quadro A: Textos de C. de Moura Castro na Revista Veja (junho de 2006-fev. de 2008)

\begin{tabular}{|c|c|}
\hline 1. Fevereiro de 2008 & $\begin{array}{l}\text { Salário de professor: A experiência dos estados mais } \\
\text { bem-sucedidos mostra que consertar a educação requer } \\
\text { muito mais do que jogar dinheiro no sistema }\end{array}$ \\
\hline 2. Janeiro de 2008 & $\begin{array}{l}\text { Ecologia seiscentista: Se as Ordenações Filipinas } \\
\text { fossem vigentes e cumpridas, hoje, os problemas de } \\
\text { desmatamento e queimadas no Brasil estariam } \\
\text { resolvidos }\end{array}$ \\
\hline 3. Dezembro de 2007 & $\begin{array}{l}\text { Guerras simbólicas: Há baronatos ideológicos que se } \\
\text { digladiam com obstinação. Examinemos um caso } \\
\text { presente: educadores versus economistas }\end{array}$ \\
\hline 4. Novembro de 2007 & $\begin{array}{l}\text { Aposentadoria de presidente: Alguns ex-presidentes } \\
\text { pedem que os esqueçam, outros fazem futrica política. } \\
\text { Bill Clinton criou um genial esquema de recrutamento } \\
\text { do empresariado internacional para as causas da } \\
\text { educação, saúde, meio ambiente e pobreza }\end{array}$ \\
\hline 5. Outubro de 2007 & $\begin{array}{l}\text { Falsos estágios?: A legislação brasileira já conseguiu } \\
\text { varrer do mapa o milenar sistema de aprendizagem. É } \\
\text { perfeitamente esperado que agora se dedique a destruir } \\
\text { os estágios }\end{array}$ \\
\hline 6. Setembro de 2007 & $\begin{array}{l}\text { (O)caso dos cursinhos?: Parece irreversível a perda de } \\
\text { espaço e de prestígio dos cursinhos. Vários fecharam, e } \\
\text { os que sobraram tendem a ter menor distinção. Mas os } \\
\text { melhores empresários do setor migraram para o ensino } \\
\text { regular, em que tiveram enorme êxito }\end{array}$ \\
\hline 7. Agosto de 2007 & $\begin{array}{l}\text { Satanás apostilado?: Há claros indícios de que os } \\
\text { apostiladores criaram uma solução brasileira de } \\
\text { grandes méritos e originalidade para a educação }\end{array}$ \\
\hline 8. Julho de 2007 & $\begin{array}{l}\text { Sociedade iterativa: Aumentou a busca de soluções } \\
\text { pelo caminho iterativo, de tentativa e erro, em } \\
\text { substituição ao foco, ao raciocínio, à concentração e à } \\
\text { elaboração intelectual }\end{array}$ \\
\hline 9. Junho de 2007 & $\begin{array}{l}\text { Política e educação: Como a qualidade da educação } \\
\text { não é valorizada pela sociedade, melhorá-la não traz } \\
\text { nenhum prêmio político }\end{array}$ \\
\hline 10.Março de 2007 & $\begin{array}{l}\text { Diploma e monopólio: Os pobres com pouco estudo } \\
\text { devem competir pelos empregos que o mercado } \\
\text { oferece. Mas para quem tem curso universitário o } \\
\text { mercado é protegido por lei }\end{array}$ \\
\hline 11.Fevereiro de 2007 & $\begin{array}{l}\text { A tríplice aliança: O empresariado tem ajudado a } \\
\text { melhorar a educação pública. Num primeiro momento, } \\
\text { socorre na manutenção das escolas, promove festas e } \\
\text { dá dinheiro. Com o tempo, as iniciativas se tornam } \\
\text { mais ambiciosas, dando lugar a programas criativos e } \\
\text { eficazes }\end{array}$ \\
\hline 12.Janei & $\begin{array}{l}\text { Autópsia de um fiasco: Precisamos dissecar } \\
\text { cuidadosamente nosso ensino defunto e responder por }\end{array}$ \\
\hline
\end{tabular}




\begin{tabular}{|c|c|}
\hline & que nossos alunos não aprendem \\
\hline 13.Dezembro de 2006 & $\begin{array}{l}\text { Uma sociedade atrasada: Há pouca confiança nas } \\
\text { instituições e no governo. Pensa-se que eles existem, } \\
\text { sobretudo, para beneficiar os homens públicos. É o } \\
\text { dinheiro que faz a burocracia andar. Que país é esse? }\end{array}$ \\
\hline 14. Novembro de 2006 & $\begin{array}{l}\text { As crendices do vestibular: } O \text { vestibular é um dos } \\
\text { maiores focos de crendices e antipatias, por ser um } \\
\text { ícone da meritocracia, tão avessa aos gostos } \\
\text { tupiniquins }\end{array}$ \\
\hline 15.Outubro de 2006 & $\begin{array}{l}\text { Sociedade cordial: Quem sabe, por falta de } \\
\text { hecatombes, a história deixou de nos ensinar a tomar } \\
\text { decisões duras e penosas, as que cortam na carne, as } \\
\text { que pisam nos calos de muitos }\end{array}$ \\
\hline 16.Setembro de 2006 & $\begin{array}{l}\text { A república do papel: A regra, criada para controlar o } \\
\text { mundo real, progressivamente transmigra para o } \\
\text { controle de papéis que pouco têm a ver com os } \\
\text { comportamentos a coibir }\end{array}$ \\
\hline 17.Agosto de 2006 & $\begin{array}{l}\text { A vingança de Fred: As práticas de Taylor se tornaram } \\
\text { o cotidiano de quem opera em empresas de primeira } \\
\text { linha }\end{array}$ \\
\hline 18.Julho de 2006 & $\begin{array}{l}\text { O brasileiro da Nokia: De quantos anos de } \\
\text { escolaridade precisará um funcionário da empresa } \\
\text { finlandesa no Brasil para se equiparar a um colega da } \\
\text { matriz? }\end{array}$ \\
\hline 19.Junho de 2006 & $\begin{array}{l}\text { A idolatria do diploma: O próprio MEC é pródigo em } \\
\text { prestigiar diplomas e em desvalorizar a experiência e a } \\
\text { competência }\end{array}$ \\
\hline
\end{tabular}

Elaborado a partir dos artigos disponibilizados no site: http://www.claudiomouracastro.com.br/

$\mathrm{Na}$ verdade, um aperitivo, pois neste trabalho não haveria espaço para tabular o restante das matérias lidas, para que o leitor também possa perceber a orientação dada por esse articulista.

A proposta aqui não é desdizer o conteúdo das Revistas, mas devolver-lhes os pontos camuflados pelo véu da isenção, precisamente aqueles pontos caros a elas próprias - se você deseja triunfar sobre um matemático, é preciso fazê-lo matematicamente pela demonstração ou refutação (BOURDIEU, 2004, p. 2004). Da leitura longitudinal dos artigos, pode-se apreender um conteúdo que: estimula a participação empresarial e desconfia das ações governamentais, principalmente para o quesito alocação de recursos.

CMC (nos artigos do Quadro A) defende maior participação dos empresários na Educação, a ponto de analisar o mercado educacional e 
aconselhar a emigração daqueles do ramo dos cursinhos para o ensino regular, a ponto de defender o sistema de apostilas (controlado por umas poucas escolas particulares) ao ensino público. A princípio ele defende o caminho da meritocracia, de que o sistema se volte apenas aos melhores. A opção teórica pela meritocracia exigiria desenvolvimento e debate, porém a que se encontra na Revista, consubstanciada em CMC, parece ser uma das mais toscas, distante de toda discussão clássica liberal. Entretanto, nossa problematização não está nesse ponto, pois é uma perspectiva teóricopolítica possível. O problema está no não-dito, na adesão corporativista a um segmento, no caso ao dos empresários, de forma disfarçada e na produção de uma ciência hispostasiada.

[...] a má qualidade do nosso ensino não pode ser explicada pelos salários dos professores. [...] com níveis salariais parecidos, as escolas privadas - não apenas as de elite - atraem melhores professores e os mantêm contentes (CASTRO, 2008).

CMC argumentou que não é necessário pagar melhor aos professores e diz que quem discordar dessa afirmativa que trate de demonstrar que os números estão errados (ibid.).

O uso de retórica é evidente, ainda que se mostre que os números estão errados, será em que veículo, na "seção cartas" da Revista? E dizer que, onde professores ganham bem o ensino não melhora, sem contextualizar, sem qualificar quanto, em que condições e comparado a quê... é o mesmo de dizer que o salário dos policiais não influi na corrupção ou que uma remuneração mais digna para os médicos não é importante à saúde pública. Ainda que a intenção fosse mostrar que há mais elementos na estrutura para consertar, não pode desconsiderar um dos mais importantes. Qual a verdadeira intenção de uma matéria que tenta desvincular a valorização do profissional da valorização da educação? Vamos ao Kamel.

Ali Kamel tem formação em Ciências Sociais e Jornalismo escreveu um livro (KAMEL, 2006) em que se posiciona contra a institucionalização do racismo através das cotas, com grande repercussão. 
O também escritor Ali Kamel foi escolhido não somente por seu cargo de chefia, mas por conta de um de seus artigos (original do jornal “OGLOBO" de 18/09/2007) que gerou até uma reportagem de capa da Revista Época intitulada "O que estão ensinando às nossas crianças?" (ÉPOCA, 22/10/2007). O texto desencadeou as mais variadas reações, contra e a favor. Destarte, a matéria de outubro de 2007 de "Época" certamente ficou a favor ${ }^{11}$. A maior preocupação de Kamel em tal texto era denunciar o conteúdo ideológico esquerdista dos livros didáticos. Com Kamel de forma recorrente encontramos o posicionamento contrário às cotas, mas especificamente às cotas raciais, o temor ao socialismo (e resistência às críticas do capitalismo) e a defesa de um discurso nãoideológico. Kamel na análise dos livros didáticos acusa que há uma tentativa de fazer nossas crianças acreditarem que o capitalismo é mau e que a solução de todos os problemas é o socialismo (ÉPOCA, 2007). Nossa questão não é refutar tal frase, mas ver como Época (estimulada pelo artigo de Kamel) constrói sua argumentação. Vê-se que a Revista Época é mais refinada que a Veja, traz mais interlocutores e assume algumas vezes a presença inescapável do ideológico. Entretanto, eis uma passagem nessa matéria (ibid.), em que a revista se opondo a uma apostila que considera esquerdista propõe essa retratação:

Os Estados Unidos têm uma das mais antigas e sólidas democracias do mundo. Sua influência em outros países se deve também à pujança de sua economia, alcançada graças a um sistema que incentiva a inovação constante e que permite a criação de novas tecnologias, como internet, ou remédios. A globalização é um fenômeno irreversível e com muitos aspectos positivos, como o investimento de países mais ricos nos mais pobres. A vitória do capitalismo deve-se ao fracasso dos regimes socialistas, de economia planejada, que resultou no fim da Guerra Fria. Se não tivesse produzido mais ganhos que perdas, o capitalismo estaria em extinção (ibid.).

\footnotetext{
${ }^{11}$ Antes mesmo da reportagem de capa, a Revista Época investiu em reportagens com o mesmo assunto na edição de 24 de setembro de 2007 escrita por Leandro Loyola e de 8 de outubro por Nelito Fernandes.
} 
Da Globalização somente os aspectos positivos são destacados. Quer dizer, a Revista é tão panfletária quanto a apostila que ataca. Ideologia por toda parte.

\section{À análise propriamente dita dos textos!}

Ou seja, a tarefa da crítica é, vamos dizer assim, fazer falar o silêncio, colocar em funcionamento um pensamento que possa desvendar todo o silêncio contido em outros pensamentos, em outros discursos... (Marilena Chauí).

Desde o início deste trabalho a tarefa principal é apreender o discurso estruturado das revistas semanais advindo de seus intelectuais orgânicos e das intenções não declaradas, escondido pelo véu da isenção e da objetividade \{em matéria da Veja de 20/08/2008, Gustavo Ioschpe propõe que os professores sejam politicamente neutros, como ele assumidamente se coloca - numa palavra: positivismo ${ }^{12}$. Definitivamente, parafraseando Maingueneau (op. cit.), é mostrar (mais uma vez) que essas instituições "mediadoras" lêem a realidade à sua maneira.

Claro que isso é feita à luz de nossa interpretação. Cada material de análise exige que seu analista, de acordo com a questão que formula, mobilize conceitos que outro analista não mobilizaria, face a suas (outras) questões (ORLANDI, 2005, p. 27). O diferencial desse procedimento nesta pesquisa foi perceber que alguns dos elementos de nossa hipótese não estavam ocultos, alguns estavam explicitamente colocados em algumas das reportagens, até de forma cínica \{a Veja de 12/09/2007, matéria de Marcos Todeschini, traz uma frase lapidar de um diretor de escola: "para nós, encarar a educação como negócio não é sacrilégio"\}.

Um desses elementos explícitos é a culpabilização do professor e a dissociação da valorização de seu salário com a melhoria do ensino \{ponto caro às revistas. A Veja de 17/09/2008, matéria de Camila Pereira, com o título "Educação é dinheiro" traz do entrevistado o seguinte: "aumento de

\footnotetext{
${ }^{12}$ Nesta parte daremos assim as referências das revistas e com nossos comentários, entre chaves \{em fonte Arial\}, semelhante à idéia de lead (lide ou sublide) dos textos jornalísticos.
} 
salário [do professor] não influencia a qualidade do ensino". A Época de 27/08/2007, de Ana Aranha, traz o título interno "Só aumento não resolve" e essa frase: "Não devemos dar nada aos professores sem que eles nos garantam uma contrapartida". As revistas tentam naturalizar que o correto é extrair o máximo do professor dando-lhe o mínimo (ou o insuficiente)\}. O que realmente está sendo ocultado é a construção de tais posicionamentos, os números estatísticos, as pesquisas e pesquisadores "adversários", consequentemente se oculta um debate mais equilibrado e, o mais importante, esconde-se o compromisso tácito que tem as revistas com seus patrocinadores.

\section{Um breve levantamento bibliográfico}

Para contribuir com o nosso trabalho fizemos levantamento bibliográfico primeiramente no Banco de Teses da Capes ${ }^{13}$ e depois entre os trabalhos do GT 16 "Educação e Comunicação" da Associação Nacional de Pós-Graduação e Pesquisa em Educação - Anped, de 2000 até 2008. De maneira geral, as pesquisas especificamente com a mídia impressas são residuais, apareceram estudos mais gerais sobre Mídia, ou seja, englobavam também a TV, a Web, rádio, etc. A TV é a mídia mais estudada e as questões que envolvem a Internet crescem rapidamente ${ }^{14}$.

Das obras levantadas no Banco de Teses, uma especialmente se destacou por ter um objeto de estudo próximo do nosso, foi a tese de doutorado de Vera Gerzson (2007). A Tese procurou mostrar o conteúdo ideológico neoliberal das revistas Veja, Época e também e "Istoé”, para o tema "Educação" entre 2003 e 2005. A tese de Vera Gerzson torna-se uma importante referência para quem se propõe a iniciar um trabalho semelhante, eis um dos pontos de sua conclusão:

[...] a educação é encarregada de cumprir sua parte para o "desenvolvimento" e o sucesso dos sujeitos e das sociedades neoliberais. O tratamento da educação como mercadoria, a rentabilidade e a mercantilização do

\footnotetext{
${ }^{13}$ Cf. http://servicos.capes.gov.br/capesdw/

${ }^{14}$ Disponibilizados no site: www.anped.org.br.
} 
conhecimento estão presentes nas páginas das três maiores revistas informativas brasileiras (GERZSON, 2007, p. 153).

Este nosso estudo complementa o dela porque é feito num período mais recente, porém, também se diferencia pela construção da análise. O conteúdo ideológico das revistas para nós é um pressuposto, o mérito de Gerzson foi capturar delas as orientações que evidenciariam ser um projeto de característica neoliberal. Destarte, não daríamos grande contribuição em dizer que tais revistas são neoliberais. Para nós o mais importante agora seria a desconstrução do projeto político das revistas, nos itens que, na aparência, lhes seriam mais caros: cientificidade, isenção, imparcialidade e democracia.

\section{Retornando à nossa interpretação}

Outra forma de questionar às revistas é trazendo delas as contradições e atos falhos. De maneira geral, elas insistem num programa de educação que garanta espaço privilegiado às escolas privadas, mas quando precisam reconhecer o sucesso de algum projeto integralmente público colocam ressalvas. \{Na reportagem de Época de 14/07/2008, intitulada "Quando a pública ganha da particular", seus autores sugerem que após garimpar encontraram algumas escolas públicas de qualidade, apontaram as do Distrito Federal, sem evidenciar que é um dos que proporciona melhor salário. Na reportagem "Prova do Fracasso" (título do sumário) de 03/10/2008 da Veja, a repórter Camila Pereira não comenta que as piores universidades são as particulares. O mesmo acontece na reportagem de Época de 05/05/2008, de Ana Aranha, a maior parte das piores universidades de medicina é particular. E noutra matéria, a Revista Época aponta com ressentimento que há 5 escolas federais entre as 20 melhores do Enem, apesar da proporção, talvez desconfie que nelas a história de sucesso é de alunos desprovidos, de 07/04/2008. Noutros momentos apresentam sua ideologia in natura, como acontece na reportagem de Marcos Todeschini, na Veja de 21/09/2008, onde aponta que as instituições particulares são as que mais emprega, pois obviamente são voltadas ao mercado, entretanto não 
traz números comparativos\}. E quando Veja encontrou uma escola particular que valorizava o professor, restringiu-se a dizer que ela combina metas curriculares bem estabelecidas, professores preparados para executá-las e um sistema desenhado para cobrar resultados (VEJA, 2007). A Veja excluiu da conclusão o item "incentivo e salários bem pagos aos docentes", a despeito do que havia no restante da matéria.

Noutra contradição dão preferência em entrevistar pesquisadores estrangeiros, mas que surpreendentemente leram nossos educadores. $\{\mathrm{Na}$ época de 21/05/2007, o repórter Marcos Bahé entrevista um pesquisador americano, David Cavallo, leitor de Paulo Freire e Miguel Arroyo\}.

Uma tarefa que se prestam as Revistas é servir de guia às classe abastadas, muitas são as matérias para indicar as melhores escolas, como estudar no exterior, etc. \{Reportagem de Luciana Vicária, de 12/11/2007, traz o título "A opção de estudar fora" e na Veja de 06/09/2006 com o título "Pós-graduação no exerior"\}. Destarte, uma opção condizente com o público alvo das revistas. Porém, quando se põem a discutir pontos que envolvem os menos abastados, como as cotas, por exemplo, não trazem o debate, se apresentam ortodoxos na posição "contra", sintetizam tudo na questão racial \{Isso pode ser visto na Época de 05/05/2008 na matéria "Discriminação não é solução" e de forma mais contundente na Veja de 23/05/2007, matéria de Marcelo Bortoloti, com o título "Intolerância"\}. Assuntos como Educação de Jovens e Adultos - EJA e Educação Inclusiva não aparecem.

As pesquisas educacionais utilizadas como referências são, na maioria das vezes, americanas, enquanto que as nossas - certamente em menor número (e nunca terão apoio dessas revistas) - são desprestigiadas. \{Todos os exemplos a seguir tem pesquisa ou modelo educacional americano como referência: as matérias de Época sobre superdotados de 26/11/2007 e sobre redução de crime e educação de 24/09/2007, etc.; e as matérias de Veja sobre Mestres Brilhantes de 15/10/2008 e sobre Educação Infantil de 18/04/2007\}. 
Um ponto caro recorrente às duas revistas é mostrar que não faltam investimentos para educação, pois o problema está na má utilização dos recursos. O interessante que isso é tão importante quanto colocar a Educação como redentora de todos os males, social, econômico, político, etc. A Educação não precisa receber investimento, mas ela será responsável por mudar todo o restante da sociedade, ainda que ela dependa do político e do econômico (o que vem primeiro, o ovo ou a galinha?). Gustavo Ioschpe da Veja tem um trecho que representa bem essa perspectiva liberal de educação: [...] silenciosa e pacífica, [o conhecimento/ a educação] é a verdadeira redentora: perto de dominar a eternidade representada pelo saber, desapropriar uma fábrica ou fazenda parece brincadeira de criança (IOSCHPE, 2008). O direito de Gustavo Ioschpe pensar isso é inquestionável, o problema que nessa mesma reportagem ironiza a quem pensa diferente, desqualifica seus adversários politico-ideológicos:

[...] a maioria de seus autores se confunde com qualquer operação matemática ou estatística que requeira sofisticação maior do que calcular o troco do táxi e costuma, convenientemente, mascarar essas deficiências sob um discurso ideológico [...] (ibid.).

O mais interessante é que aponta ideologicamente o quanto os outros são ideológicos.

No quesito "perseguição implacável à perspectiva de esquerda", sem dúvida que as duas se propõem a isso, como vimos, por exemplo, na preocupação de Época com os livros didáticos. De qualquer forma, ninguém supera a Veja. Nos últimos anos, a Veja tem se especializado, segundo jargão do jornalismo, em lacerdismo ou jornalismo apologético, que seria a defesa exacerbada de um ponto de vista. O que seria um problema menor, caso a revista assumisse isso. Na verdade, a ética tem sido pouco prestigiada na revista, há pouco espaço para "direito de resposta" e os adversários da revista são atacados vorazmente. Educadores como Paulo Freire, com uma história decorosa (contraditoriamente reconhecida em outras revistas do Grupo Abril, cf. NOVA ESCOLA, 2008), é atacado de forma vil. A matéria mais emblemática da Veja foi uma intitulada "Prontos para o século XIX", 
parte da reportagem de capa de 20/08/2008, de Monica Weinberg, Camila Pereira e participação de Camila Antunes e Marcos Todeschini, em que se encontra trecho como esse:

Muitos professores brasileiros [...] idolatram personagens arcanos sem contribuição efetiva à civilização ocidental, como o educador Paulo Freire, autor de um método de doutrinação esquerdista disfarçado de alfabetização (VEJA, 20/08/2008).

Paulo Freire foi Doutor Honoris Causa em várias universidades no mundo, até naquelas reverenciadas pela revista ${ }^{15}$. A matéria do dia 20/08/2008 corou um movimento interno da Revista, que parece uníssona entre seus articulistas, onde explicita um desrespeito enorme aos professores e traz muito acentuada a visão economicista, positivista.

Na Veja e na Época não há espaço para uma educação que não seja tecnicista, supostamente neutra, meritocrática (por isso não pode ser para todos) e, contraditoriamente, redentora. Mas, pode-se afirmar que na Veja é ainda pior - provavelmente também para outros temas - porque em boa parte de suas matérias passa o desrespeito, a falta de democracia e até a falta de ética. $\{\mathrm{Na}$ carta dos eleitores do dia 27/08/2008, 269 pessoas comentaram o tema de capa da semana anterior, somente 4 foram publicadas, 3 a favor da revista e apenas 1 contra, esta com apenas um parágrafo de um professor difamado na matéria...\}. Isso foi o que apreendemos da maior revista semanal do país.

\section{Considerações finais (aos educadores críticos)}

O rei está nu!

(Hans Christian Andersen)

Alguns trabalhos de análise precisam ser permanentemente realizados, a despeito de seu teor evidentemente político, de forma rigorosamente científica, para que se acumule um conhecimento mais sofisticado, menos ressentido e menos panfletário.

${ }^{15} \mathrm{Cf}$. http://www.paulofreire.org/Institucional/PauloFreire 
[Não é fácil] identificar em cada caso, estaticamente (como imagem fotográfica instantânea), a estrutura; de fato, a política é - em cada caso concreto - o reflexo das tendências de desenvolvimento da estrutura, tendências que não se afirma que devem necessariamente se realizar (Gramsci, 1981, p. 118).

Não é fácil apreender uma conjuntura histórico-política, menos ainda como ela se liga à estrutura da sociedade. Não obstante, ainda com Gramsci, podemos acrescentar que os encaminhamentos políticos, embora não sejam ilimitados por conta de uma estrutura de transformação lenta, são certamente inúmeros. O "silenciamento" dos intelectuais contrahegemônicos é muito grave porque atrapalha o vislumbre de outras possibilidades. O silêncio desses intelectuais não vem somente da apatia, da acomodação ou da perplexidade, mas de um processo que procura mantê-los sob controle, em espaços de pouca repercussão, aprisionados na própria academia. Enquanto isso, os intelectuais da hegemonia burguesia se mostram livres para defender teses e posicionamentos há muito tempo criticadas e desqualificadas (como a teoria do capital humano, a educação como panacéia dos problemas sociais, a culpabilização dos professores, o tecnicismo, etc.). Cabe aos intelectuais à esquerda, constituir uma filosofia (da práxis) que:

Não tende a deixar os "simples" na sua filosofia primitiva do bom-senso; antes, busca orientá-los para um conceito superior da vida. Quando afirma a necessidade do contato entre os intelectuais e os "simples" não o faz para restringir a atividade científica e preservar a unidade no nível inferior das massas, mas precisamente para construir um bloco intelectual-moral capaz de tornar politicamente possível o progresso intelectual das massas e não apenas de pequenos grupos intelectuais (Gramsci apud JOLL, 1977, p. 72).

Os intelectuais orgânicos dos grandes meios de comunicação de massa veiculam seus conteúdos 'abundantemente ideológicos' para milhões de pessoas e a todo o momento, enquanto aqueles que pretendem trabalhar na contra-hegemonia veiculam em espaço com um alcance muito menor. Não obstante, o pior que os Educadores Críticos podem fazer é desistir de desenvolver seus posicionamentos nos poucos espaços que restam. Alguns 
educadores críticos seniores desistem porque conhecem bem as revistas do “discurso único" e demonstram não valer a pena; enquanto outros, sobretudo os mais novos, temem expor suas posições. Ou seja, deixa-se um vasto terreno à disposição dos intelectuais da ideologia dominante e não se disponibiliza trabalhos de referência aos docentes proletarizados da Educação Básica.

A proposta aqui foi contribuir nessa direção, entretanto não era simplesmente dizer que as Revistas Época e Veja são neoliberais, mas tiralhes um debate. Um debate que precisa ser amplo, que às vezes precisará vir esmiuçado, ponto por ponto, com o cuidado de não cair numa generalização monolítica. Para cada item deve vir uma resposta, resposta para a culpabilização do professor, para a mercantilização da educação, resposta para as distorções dos dados sobre valorização do salário docente, resposta à camuflagem que realizam sobre seus próprios interesses, resposta para o programa positivista que desejam à educação formal, etc. Certamente que as repostas não serão veiculadas na mesma proporção das revistas - seria ingenuidade pensar isso -, serão apenas mais um subsídio aos docentes que com dificuldades acessam os poucos espaços de publicação nãohegemônicos.

Aqui nossa resposta foi mostrar o quanto as revistas são ideológicas, mas chegamos ao ponto de perceber o quanto são panfletárias, apologéticas. Devolvemos-lhes as acusações que costumam fazer. A revista Veja, especialmente, chega ao requinte de ser maledicente, manipula os números e as informações para defender seus interesses privados. $\mathrm{O}$ descaramento que a Revista Veja alcançou é um contra-senso até mesmo para o projeto meritocrático do atual capitalismo brasileiro. É assustador!

\section{Referências bibliográficas}

BOURDIEU, P. O Campo Científico. In: ORTIZ, Renato. Pierre Bourdieu. Sociologia. São Paulo: Editora Ática, 1994.

BOURDIEU, P. Os usos sociais da ciência: por uma sociologia clínica do campo científico. São Paulo: Editora UNESP, 2004. 
CASTRO. C.M. Salário de professor: A experiência dos estados mais bemsucedidos mostra que consertar a educação requer muito mais do que jogar dinheiro no sistema. In: Revista Veja, coluna Ponto de Vista. 13 de fevereiro de 2008.

CHAUÍ, M. Convite à Filosofia. São Paulo: Editora Ática, 1994.

ÉPOCA, O que estão ensinando às nossas crianças? (reportagem de capa seção Brasil). In: Revista Época. 22 de outubro de 2007.

GERZSON, V. A mídia como dispositivo da governamentalidade neoliberal: os discursos sobre educação nas revistas Veja, Época e Istoé. Tese de Doutorado. UFRGS, 2007.

GRAMSCI, A. Concepção Dialética da História. Rio de Janeiro: Civilização Brasileira, 1981.

IOSCHPE, G. Educação e capitalismo: aliados ou inimigos?. In: Revista Veja. 14 de maio de 2008.

JOLL, J. As idéias de Gramsci. São Paulo: Cultrix, 1977.

KAMEL, A. Não somos racistas: uma reação aos que querem nos transformar numa nação bicolor. Rio de Janeiro: Nova Fronteira, 2006.

KONDER, L. O Futuro da Filosofia da Praxis: o pensamento do marxismo no século XXI. Rio de Janeiro: Paz e Terra, 1992.

KONDER, L. Filosofia e Educaşão: de Sócrates a Habermas. Rio de Janeiro: Forma \& Ação, 2006.

KOSIK, K. Dialética do Concreto.(2 edição) Rio de Janeiro: Paz e Terra, 1976.

MAINGUENEAU, D. Novas Tendências em Análise do Discurso. 3ª . Ed. Campinas - São Paulo: Editora Unicamp, 1997.

MARX, K; ENGELS, F. A Ideologia Alemã. São Paulo: Editorial Grijalbo, 1977.

NOVA ESCOLA. Paulo Freire: o mentor da educação para a consciência. Edição Especial. In: Nova Escola. 08 de outubro de 2008. Disponível em http://revistaescola.abril.com.br/historia/pratica-pedagogica/mentoreducacao-consciencia-423220.shtml. Capturado em agosto de 2009.

ORLANDI, E. Análise do Discurso: princípios e procedimentos. $6^{\mathrm{a}}$ ed. Campinas - São Paulo: Pontes, 2005.

SADER. E. Por que a Veja mente, mente, mente, desesperadamente? In: Carta Maior de 30/10/2005. Disponível em: http://www.cartamaior.com.br/templates/colunaMostrar.cfm?coluna $\mathrm{id}=226$ $\underline{3}$ Capturado em fevereiro de 2009. 
VEJA. "Prontos para o século XIX" e "Você sabe o que estão ensinando a ele?". [partes referentes à Reportagem de Capa]. In: Revista Veja. 20 de agosto 2008.

VEJA. A lição do Piauí/A escola campeã no ranking do MEC segue uma cartilha que deu certo em outros países: investe nos professores. In: Revista Veja. 28 de fevereiro, 2007. 